\title{
Exploration on the Improvement of Innovation Ability of Civil Engineering Specialty Students under the Background of New Engineering
}

\author{
Chuang Chen \\ School of Civil Engineering and Architecture \\ Ningbo Institute of Technology, Zhejiang University \\ Ningbo, China \\ chenchuang@nit.zju.edu.cn \\ Zheng Luo \\ School of Civil Engineering and Architecture \\ Ningbo Institute of Technology, Zhejiang University \\ Ningbo, China \\ lz225610@163.com
}

\author{
Yinhui Wang* \\ School of Civil Engineering and Architecture \\ Ningbo Institute of Technology, Zhejiang University \\ Ningbo, China \\ wangyh7244@nit.zju.edu.cn \\ Zuguang Bian \\ School of Civil Engineering and Architecture \\ Ningbo Institute of Technology, Zhejiang University \\ Ningbo, China \\ bzg@nit.zju.edu.cn
}

\author{
Jianghong Mao \\ School of Civil Engineering and Architecture \\ Ningbo Institute of Technology, Zhejiang University \\ Ningbo, China \\ jhmao@nit.zju.edu.cn
}

\begin{abstract}
Under the background of new engineering, new requirements are put forward for training the innovation ability of traditional civil engineering students. Educators must adapt to the current social development environment and explore new ways to improve students' innovation ability to ensure talents adapt to social and technological development. This study takes bridge engineering specialty as a case study to explore a new paradigm to improve the innovation ability of professional talents. In four aspects of teaching goals, teaching contents, teaching methods, examination and evaluation, the specific teaching reform content and the specific implementation method was proposed. The education reform requires to strengthen students' innovative thinking, innovative consciousness and innovative ability training. Meantime, it is important to improve students' engineering innovation ability to analyze and solve complex engineering problems using both emerging technologies and traditional knowledge. Therefore, high-level applied talents can be cultivated to meet the requirements of industrial development and industrial transformation and upgrading.
\end{abstract}

Keywords-exploration; innovation ability; civil engineering specialty students; new engineering

\section{INTRODUCTION}

Under the background of the new engineering, civil engineering talents guide training needs to transfer from the traditional engineering-oriented training to results-oriented training. Not only should educators pay more attention to the cultivation of students' qualities in engineering and technology

Zhejiang Province Higher Education "13th Five-year" Teaching Reform Research Project (jg20180442) theory, but also we should be guided by the development of the industry and the future demand of engineering. We will strengthen the cross-integration with emerging technologies such as informatization, digitization and intelligentization, to cultivate students' innovative thinking, innovative consciousness and innovative ability. So, the students can truly to satisfy the requirements of regional economic development and to provide support for industry development and industrial transformation and upgrading. Therefore, the main goal is to explore new ways to improve the innovation ability of civil engineering major students under the background of new engineering, and systematically form a teaching paradigm of engineering innovation ability cultivation focusing on the cross-boundary integration of emerging technologies (informatization, digitization and intelligentization) and traditional specialty methodology.

\section{OPPORTUNITY AND CHALLENGE}

A. The cultivation of innovation ability of engineering students is a new requirement for the training of traditional civil talents in the new engineering construction.

With the rise of the new economy and the arrival of the new industrial revolution, traditional engineering education is facing severe challenges. Since February 2017, the ministry of education of China has actively promoted the construction of new engineering projects, and successively formed the "Fudan 
Consensus", "Tianda Action" and "Beijing Guide". These projects are in an effort to explore and form a Chinese model and experience that leads the global engineering education, and contribute to the building of a strong country in higher education. Under the background of new engineering construction, the concept of engineering education has changed from passive adaptation service to active leading development. The mode of talent cultivation has changed from subject and specialty division to cross-boundary integration. The education and teaching process has changed from knowledge teaching to engineering ability teaching ${ }^{[1]}$. Therefore, it can be seen that the new engineering requires talent cultivation to be oriented to satisfy the requirements of engineering development, and to play a leading role in the future industry development. In the cultivation mode, the emphasis is on interdisciplinary and cross-border integration, and in the cultivation method, the emphasis is on the cultivation of engineering ability.

The outline of the national medium-term and long-term education reform and development plan clearly puts forward "improving students' ability of practice, innovation and learning", which requires students to have the ability to solve practical engineering problems on the premise of mastering theoretical knowledge ${ }^{[2]}$. The construction of new engineering should actively serve the national strategy of innovation-driven development. Colleges and universities should constantly improve the education system of "creative-innovationentrepreneurship" for new engineering talents. They should also integrate the education of innovation and entrepreneurship into the whole process of talent cultivation, and focus on cultivating students' innovative spirit, entrepreneurial consciousness and innovation and entrepreneurship abilities ${ }^{[3]}$. It can be seen that the cultivation of engineering innovation ability is a new requirement and proposition of new engineering construction for traditional engineering specialties.

Regression engineering has become the mainstream direction of the engineering education reform. It is the only way for the engineering education reform under the new engineering background to transform from the traditional "subject-oriented" training concept to "results-oriented" training concept. However, how to construct the relationship between science, technology and engineering in the process of talent cultivation has become a hot issue in teaching reform. One-sided adhere to scientific knowledge, basic knowledge (mathematics, physics, chemistry) and technical knowledge (mechanics, materials science, structural mechanics) teaching for the purpose of teaching concept can ignore the engineering practice, or ignore the engineering development direction. This can lead to talent cultivation and the engineering practice out of touch. It is particularly prominent in traditional civil engineering specialties.

Civil engineering specialty is a traditional major with a long history. It is supported by traditional disciplines such as mechanics, civil engineering disciplines, which causes that its talent training course system is relatively curing. Systemic requirement of basic knowledge of scientific knowledge and technology is very high. Although the emphasis on engineering practice has always been the tradition of civil engineering majors, the practice process is often too stylized. This is out of touch with the forefront of engineering development.
Especially in the era of new industrial revolution characterized by informatization, digitization and artificial intelligence, the civil construction industry must rise to the occasion. The training mode of civil engineering professionals is far away from the needs of civil construction engineering industry, so reform is imminent. However, the core of reform is to strengthen the cultivation of engineering innovation ability.

\section{B. Multi-disciplinary engineering innovation ability cultivation is a new form of civil engineering talents cultivation under the background of new engineering}

New engineering construction consists of three paths: (1) different engineering disciplines cross and merge to form new engineering majors; (2) nurturing and developing majors from basic subjects that meet the requirements of new technologies and new industries in the future; (3) forming new majors from transforming and extending the traditional engineering subjects ${ }^{[4]}$. Civil engineering majors belong to traditional engineering majors. Informatization, digitization and intelligent transformation and extension are the new forms of talent cultivation of civil engineering majors under the background of new engineering.

"Fudan Consensus" clarifies that under the background of new engineering local universities should play a supporting role in regional economic development, industrial transformation and upgrading. Therefore, civil engineering majors should cultivate high-level applied talents supporting the transformation and upgrading of the civil construction industry. Civil construction industry is a traditional industry, but in recent years, under the pushing of information technologies and modern industrial technologies of the construction industries from the government, it is developing rapidly. In the construction, operation and management of the Hongkong-Zhuhai-Macao Bridge and a large number of national major infrastructure projects, BIM technology, GIS technology, Internet, Internet of things, smart sensor technology, intelligent robot, mechanical assembly emerging technology, these emerging technologies are being used in large numbers. The practice has proved that the traditional civil construction industry can blossom into a new vitality based on the continuous development of information, digital, intelligent technology. The traditional training of civil engineering professionals must adapt to the new development needs of civil construction industry and lead the development of engineering technology and industrial transformation and upgrading. Therefore, only by integrating information technology, big data technology and intelligent sensing technology to carry out engineering innovation ability training with civil and architectural engineering as the background, students' ability to solve practical problems can really be improved.

To sum up, under the guidance of new technology and industrial revolution, the active integration of information technology, digital technology and intelligent technology has become an urgent demand for the development of civil industry. As a traditional engineering major with a long history, civil engineering major needs to blossom into a new vitality under the background of new engineering. In response to the new engineering construction, colleges and universities have also carried out a series of exploration and thinking on the 
construction of talent training mode. Yunnan Agricultural University, based on the analysis of the main problems existing in urban and rural construction discipline and specialty group, puts forward the innovative talent cultivation mode under the cross-integration of urban and rural construction disciplines, which provides certain guidance and reference for the quality of civil engineering personnel training ${ }^{[5]}$. North China University of Water Resources and Hydropower has also proposed that local colleges and universities should reform the mode of talent cultivation and strengthen the research on new engineering to improve the employment competitiveness of engineering college graduates under the background of new engineering ${ }^{[6]}$. Sun ${ }^{[7]}$, from Huazhong University of Science and Technology, deem that civil engineering specialty as a traditional engineering needs to adapt to the new requirements of cultivating talents in multidisciplinary intersection, and the innovation ability is the core of the new engineering civil engineering talents training target, including the innovation thinking, innovation ability, innovation consciousness, innovation vision and professional knowledge. It is the fundamental way to improve the innovative ability of civil engineering talents in new engineering by promoting innovative thinking with interdisciplinary integration of the course system and teaching content and to enhancing innovative skills by carrying out multi-level and whole-process innovation practice.

\section{CONTENT AND METHODOLOGY}

To achieve the above goals, the Bridge Specialty is considered as a case to introduce the reform exploration, which can be carried out as the following four aspects:
A. Strengthen the basic knowledge of discipline with the goal of improving the engineering innovation ability

The foundation of innovation ability cultivation are discipline foundation and specialty foundation. Strengthening the cultivation of engineering innovation ability can not weaken the basic knowledge, but need to deepen the basic knowledge of science and technology with target and direction in engineering practice. To this end, it is necessary to take the specialized courses of civil engineering construction, road and bridge construction technology and bridge structure computer calculation as the pilot to carry out the teaching reform of strengthening the foundation of discipline and specialty with the goal of improving the engineering innovation ability. The content can be seen as Fig. 1. (1) Aiming at cultivating students' engineering practice ability, innovative thinking and innovative ability, the course contents should be optimized, meantime, the skill-based and operational courses should be simplified. Furthermore, the course content of complex technical difficulty, a high level of comprehensive application of knowledge and large scope of engineering innovation can be strengthened. (2) "Four-steps Teaching Method" including "engineering drive -- basic knowledge -- innovative thinking -practice training" can be established and practiced which can been seen in Fig. 2. Four-steps Teaching Method can be explained that the teaching content is driven by engineering cases to guide students (1) to discuss the basic knowledge and basic theories involved in solving complex engineering problems; (2) to make rational use of basic knowledge and professional knowledge to carry out innovative thinking training in engineering; (3) to complete systematic training in practice.

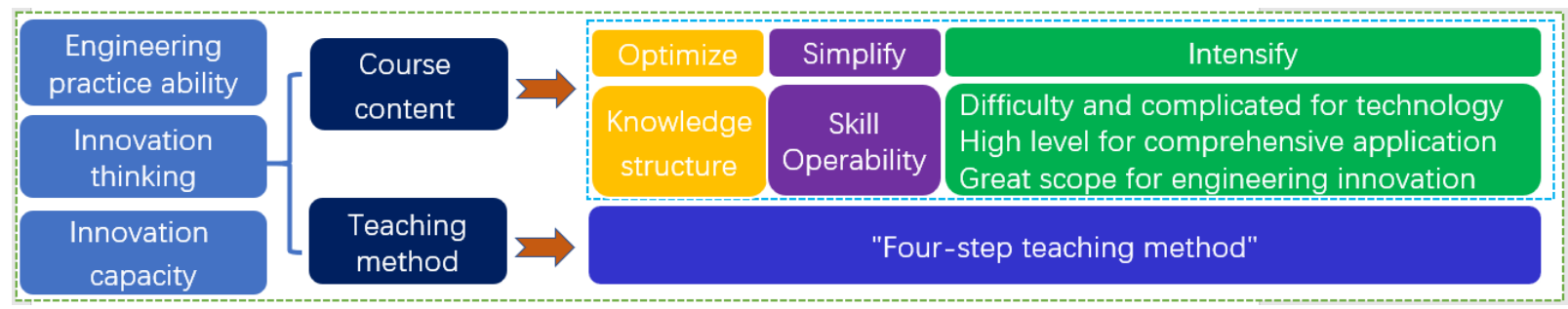

Fig. 1. Courses content and teaching method reform

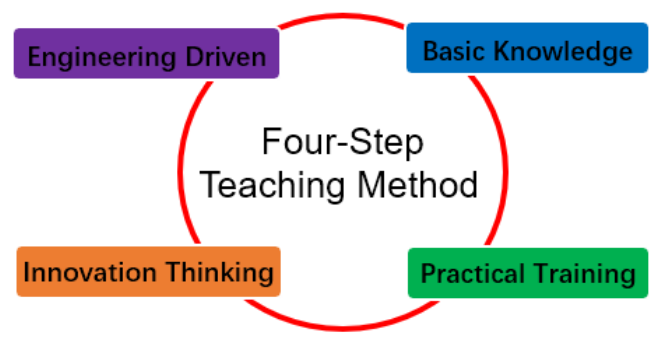

Fig. 2. Four-steps teaching method

\section{B. Construction of engineering technology innovation training based on interdisciplinary integration}

BIM technology, GIS, Internet, Internet of Things, intelligent sensing, engineering machinery and even robots have become hotspots in the civil engineering industry, and are increasingly used in the construction, operation and management of major engineering projects. The reform can take the courses of "Civil Engineering Construction", "Road and Bridge Construction Technology", "Road Engineering Maintenance”, "Bridge Reinforcement and Maintenance” and comprehensive training projects as pilots to determine the Innovative training content for assembly construction technology, road maintenance technology, bridge reinforcement and maintenance technology. The abovementioned emerging technologies and engineering technologies can be cross-integrated, and the engineering training content that meets the needs of engineering innovation ability training can be reconstructed. and use the "four-step teaching method" in teaching practice. In the construction course, the training of assembling construction technology innovation is carried out. Through the analysis of the current situation and difficulties of bridge assembling construction 
technology, students are guided to carry out technical innovation on the basis of analyzing emerging technologies such as information technology and intelligent sensing. In addition to the practical training projects within the courses, pilot projects will also be carried out in the graduation project. The teaching content of engineering practical training reform can be seen in Fig. 3.

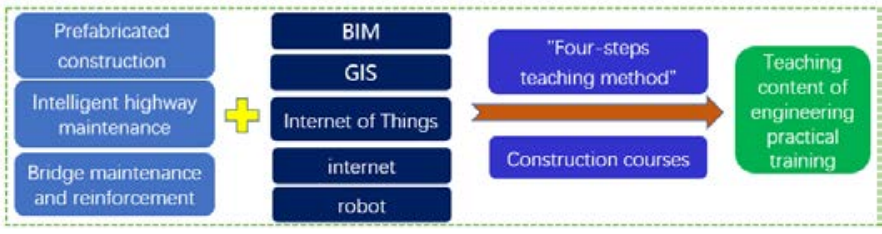

Fig. 3. Teaching content of engineering practical training reform

\section{Exploration of evaluation methods guided by the goal of improving the engineering innovation ability}

After the adjustment of teaching objectives and teaching contents, the assessment method should be carried out around the teaching objective of "improving engineering innovation ability". The assessment method should consider if the students has improved the comprehensive application ability and engineering innovation ability with professional knowledge. And whether they have the quality and ability to solve complex engineering problems with emerging technologies. According to these targets, detailed rules for the assessment and evaluation of practical training projects and courses can be formulated. The evaluation method for engineering innovation ability promotion processes can be seen in Fig. 4. The evaluation method should be combined with the creative thinking and innovation ability of students in the teaching process. At the same time, the evaluation should also encourage students to develop teamwork and creative thinking.

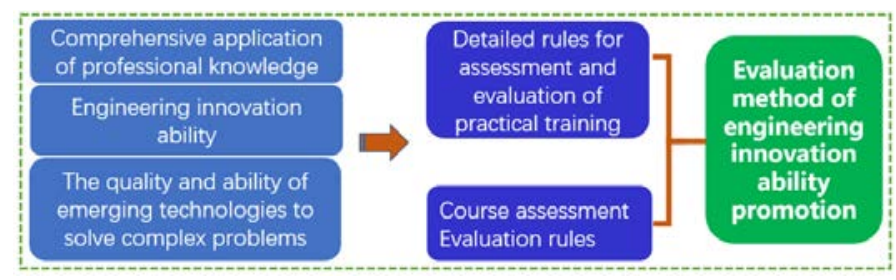

Fig. 4. Evaluation method processes

D. Establishing a new paradigm of cultivating engineering innovation ability by cross-boundary integration of emerging technologies and traditional professional technologies

On the basis of summarizing the aforementioned teaching reform and practice, the new paradigm of engineering innovation ability cultivation, which is adapted to the crossborder integration of emerging technologies such as informatization, digitization and intelligence and traditional professional technologies, is constructed from the four aspects of teaching objectives, teaching contents, teaching methods and assessment, so as to achieve the purpose of demonstration and promotion.
In addition, Open class should be organized regularly. Through communication, teaching experience of other teachers can be absorbed to improve deficiencies, and teaching experience of this project can be summarized and demonstrated in stages. Regular teaching surveys also need to be carried out. After the completion of pilot courses every year, teaching effect surveys should be carried out among students to absorb students' opinions and Suggestions on classroom teaching, which will make the reform continuous improvement.

\section{CONCLUSION}

Under the background of new engineering, civil engineering majors are faced with great opportunities and challenges. How to train talents who can adapt to the development of emerging technologies and solve practical engineering problems with emerging technologies has become the main problem of education reform. Through the exploration of the teaching reform ideas of bridge engineering major, this study comes to the following conclusions:

(1) In teaching content and teaching practice, it is necessary to combine the development of emerging technologies, and adopt the case teaching method to improve students' innovative ability to solve complex problems in practical projects.

(2) The improvement of innovation ability can be carried out from four aspects of teaching objectives, teaching contents, teaching methods and examination and evaluation. The new paradigm of engineering innovation ability cultivation can be established by combining emerging technologies and traditional professional technologies.

(3) The four-step teaching method has a wide application prospect in cultivating students' innovative ability and improving teaching methods.

\section{REFERENCES}

[1] J. J. Zhang, "Exploring the Way to Improve College Students" Employment Ability Under Background of New Engineering," Heilongjiang Researches on Higher Education, 2018(5), pp. 130-133, In Chinese.

[2] T. Feng, J. B. Wang, Y. Y. Su, Z. Y. Xu, C. Z. Guo, Y. Pu, “The Exploration and Practice of 'Project Practice Teaching' in the Background of New Engineering to Improve the Applied Technical Ability of College Students-Take 'Metal Material and Heat Treatment' as an example,” Education Teaching Forum, 2018(21), pp.155-156, In Chinese.

[3] F. B. Zhang, "Discussion on the Path and Method of New Engineering Construction -- Exploration and Practice of Tianjin University," Chinese University Teaching, 2017(7), pp. 8-12, In Chinese.

[4] Y. Wang, A. F. Zhang, "Eight Fundamental Relations in Engineering Education Reform," Higher Education Development and Evaluation, 2018, vol. 34(2), pp. 1-8, In Chinese.

[5] B. Y. Rao, H. Y. Liu, Z. B. Lu, Y. Zhao, X. Dai, Construction of Multidisciplinary Cross-integration Talent Cultivation Model in Urban and Rural Construction under the Idea of New Engineering, Journal of Yunnan Agricultural University (Social Science), 2018, vol 12(3), pp. 103-107, In Chinese.

[6] J. Yang, L. S. Han, L. J. Shangguan, Q. Y. Tan, Reforms and Practices of Talent Training Mode in Local Colleges and Universities under the Background of New Engineering - Taking North China University of 
Water Resources and Electric Power as an Example, Journal of North

China University of Water Resources and Electric Power (Social Science Edition), 2018, vol. 34(3), pp. 90-92, In Chinese.
[7] J. Sun, Innovation Ability Training of Civil Engineering based on the Program of Emerging Engineering Education, Journal of Architectural Education in Institutions of Higher Learning, 2018, vol. 27(2), pp. 5-9, In Chinese 